\title{
Identidade e representações sociais de moradores da zona sul da cidade do Rio de Janeiro acerca deles mesmos, dos moradores do subúrbio e dos cariocas
}

\author{
Identity and social representations of residents of the south of the city of Rio de \\ Janeiro about themselves, the residents of the suburbs and the Cariocas \\ Identidad y representaciones sociales de habitantes de la zona sur de la \\ ciudad de Rio de Janeiro acerca de ellos mismos, de los habitantes del \\ suburbio y de los cariocas
}

\author{
Thamiris Marques ${ }^{1}$ \\ Rosana Ferreira Chalegre ${ }^{1}$ \\ Álvaro Rafael Peixoto ${ }^{1}$ \\ Rafael Pecly Wolter ${ }^{2}$
}

Recebido em: 02/07/2018; revisado e aprovado em 14/04/2019; aceito em 02/05/2019
DOI: http://dx.doi.org/10.20435/inter.v21i2.2069

\begin{abstract}
Resumo $O$ presente artigo aborda as crenças de moradores da zona sul da cidade do Rio de Janeiro acerca deles mesmos, de pessoas que moram no subúrbio e dos cariocas em geral. O enfoque teórico é composto pela teoria das representações sociais, mais precisamente sua abordagem estrutural elucidada pela teoria do núcleo central, e a teoria da identidade social. O método envolve um questionário que inclui itens de Likert sobre o que é ser carioca, exemplificado por suas características mais marcantes, e evocações livres com os termos indutores "cariocas", "moradores da zona sul" e "moradores do subúrbio". Os participantes da pesquisa são 100 residentes da zona sul do Rio de Janeiro das regiões administrativas da Lagoa e de Botafogo. A análise de dados dos itens de Likert foi feita a partir da ANOVA e a das evocações livres foi realizada por meio da análise prototípica. Os resultados mostram que a representação social e a identidade dos moradores da zona sul parecem calcadas em características mais positivas e distintas da representação dos residentes do subúrbio. Além disso, ambas as categorias de moradores das duas zonas do Rio de Janeiro, subúrbio e zona sul, aparecem como um recorte de uma categoria maior, a categoria do carioca.
\end{abstract}

Palavras-chave: carioca; identidade; representação social; pensamento social; Rio de Janeiro.

Abstract: This article deals with the beliefs of residents of the south of the city of Rio de Janeiro about themselves, the people living in the suburbs, and the Cariocas in general. The theoretical approach is composed of the theory of social representations, more precisely its structural approach elucidated by the central core theory, and the theory of social identity. The method involves a questionnaire that includes Likert items about what it is to be Carioca, exemplified by its most striking characteristics, and free evocations with the terms "Carioca" inductors, "southern residents" and "suburban residents". The research participants are 100 residents of the southern zone of Rio de Janeiro in the administrative regions of Lagoa and Botafogo. Data analysis of Likert items was done using ANOVA and the free evocations were performed through prototypical analysis. The results show that the social representation and the identity of the residents of the southern zone seem to be based on more positive and distinct characteristics of the representation of the suburban residents. Also, both categories of residents of the two zones of Rio de Janeiro, suburban and southern zone, appear as a cut of a larger category, the category of Carioca.

Keywords: carioca; identity; social representation; social thought; Rio de Janeiro.

Resumen: El presente artículo aborda las creencias de residentes de la zona sur de la ciudad de Rio de Janeiro acerca de ellos mismos, de las personas que viven en el suburbio y de los cariocas en general. El enfoque teórico está compuesto por la teoría de las representaciones sociales, más precisamente su enfoque estructural elucidado por la teoría del núcleo central, y la teoría de la identidad social. El método implica un cuestionario que incluye ítems de Likert sobre lo que es ser carioca, ejemplificado por sus características más marcadas, y evocaciones libres con los términos inductores "cariocas", "moradores de la zona sur" y "moradores del suburbio". Los participantes de la encuesta son 100 residentes de la zona sur de Rio de Janeiro de las regiones administrativas de la Lagoa y de Botafogo. El análisis de datos de los ítems de Likert

\footnotetext{
${ }^{1}$ Universidade do Estado do Rio de Janeiro (UERJ), Rio de Janeiro, Rio de Janeiro, Brasil.

${ }^{2}$ Universidade Federal do Espírito Santo (UFES), Vitória, Espírito Santo, Brasil.
} 
fue hecho a partir de la ANOVA y el de las evocaciones libres fue realizado a través del análisis prototípico. Los resultados muestran que la representación social y la identidad de los habitantes de la zona sur parecen calcarse en características más positivas y distintas de la representación de los residentes del suburbio. Además, ambas categorías de habitantes de las dos zonas de Rio de Janeiro, suburbio y zona sur, aparecen como un recorte de una categoría mayor, la categoría del carioca.

Palabras clave: carioca; identidad; representación social; pensamiento social; Rio de Janeiro.

\section{A ZONA SUL CARIOCA: HISTÓRICO, MUDANÇAS E MORADORES}

\subsection{A criação da zona sul carioca: contextualizando o Rio de Janeiro}

A identidade das pessoas se baseia em fatos atuais, mas também por meio da história. Navegar pelo passado de uma cidade, por exemplo, pode revelar muito sobre seu presente e sobre as características de vida de sua população atual.

Realidades distintas são marcadores preciosos para definir aspectos relativos aos grupos sociais. Um exemplo disso é a realidade da zona sul da cidade do Rio de Janeiro. Existe um contraste alto entre esta e as demais regiões da cidade, tanto em termos sociais quanto econômicos e culturais.

Em um panorama histórico, Gontijo (2002) afirma que as elites que residiam no centro da cidade iam se deslocando e se instalando cada vez mais longe, indo para Botafogo, e, a partir da abertura do túnel que liga esse bairro a Copacabana, no final do século XIX, ao restante da beira do oceano. Esse fato fez surgir o que denominamos hoje de zona sul e, segundo o autor, como oposição, a zona norte.

O turismo é marca forte da zona sul, bem como suas paisagens naturais conhecidas internacionalmente. Suas belas praias, os mais altos salários e as melhores condições de infraestrutura da cidade são marcas dessa região. É notável também o fato de que a maioria dos pontos turísticos mais conhecidos do município do Rio de Janeiro se encontram nessa região, o que atrai alto fluxo de turistas e, por sua vez, gera maior fluxo também de investimentos, tanto pela entrada de capital estrangeiro como pelos investimentos governamentais necessários à manutenção do local, para recebimento desses turistas.

É interessante frisar que a mudança de visão sobre os banhos de mar e as praias em geral teve grande influência no movimento rumo à zona sul. Feijão (2013) nos indica que o comportamento em relação às praias se iniciou na Europa, onde essas foram deixando de ser frequentadas apenas para questões de saúde e passaram a ser ocupadas para o lazer e a socialização. Esse fator passou a levar também as diversas camadas da sociedade na direção do litoral. Além disso, outro fator histórico é que a pele bronzeada no início do século XX não era bem aceita como nos dias de hoje, já que uma pele clara era também um sinal de distinção social, sinal de que não se exerciam atividades ao ar livre, com algum tipo de esforço físico, especialmente para as mulheres (FEIJÃO, 2013).

Cardoso (2010) descreve como a zona sul começou a ter um delineamento a partir da criação de Copacabana e, a partir daí, outros bairros que nem sequer eram banhados pelas praias surgiram (como Laranjeiras, Jardim Botânico e Gávea), por meio do que a autora chamou de mimetismo.

Cardoso (2010) traz uma clara ilustração da dicotomia observada ao início do século XX, entre o que se passou a considerar subúrbio e zona sul, a partir de um artigo publicado no jornal "O Cruzeiro", em 1953, por Pedro Gomes (apud CARDOSO, 2010, p. 81): 
Nos dois mundos antagônicos do Rio se forjaram dois estilos de vida totalmente diversos. Aqui não falamos, é claro, de meio termo, mas do que são, caracteristicamente, a 'zona sul' e a 'zona norte'. A zona sul, que começa propriamente no Flamengo, é a civilização do apartamento, e das praias maliciosas, do traje e dos hábitos esportivos, da 'boite' e do pecado à meia-luz, dos enredos grã-finos, do 'pif-paf' de família, dos bonitões de músculos à mostra e dos suculentos brotinhos queimados de sol, dos conquistadores de alto coturno e de certas damas habitualmente conquistáveis, do 'short', do blusão e do 'slack', dos hotéis de luxo (e de outros de má reputação) e dos turistas ensolarados. O Rio cosmopolita está na zona sul, onde uma centena de nacionalidades se tropicalizam à beira das praias.

\subsection{Mudanças no cenário da zona sul carioca}

À medida que a população vinha sendo expulsa das regiões centrais da cidade, aqueles de camadas mais altas da sociedade iam se deslocando para o que hoje conhecemos como zona sul, fazendo crescer os bairros que ali se encontravam concomitantemente a uma grande valorização desse território. Regiões antes conhecidas por possuírem grande status social, como São Cristóvão, com a entrada das indústrias têxteis passam a não mais possuírem tal status, sobrepujados agora por freguesias como a da Lagoa, que possui bairros residenciais.

Também a construção de vias importantes, segundo Benchimol (1990), como a avenida Beira Mar, abriu espaço para a expansão nessa região, destinada claramente para a moradia das classes abundantes. Segundo o autor, os próprios serviços que ali cresciam se articulavam com os empreendimentos imobiliários, tanto nos bairros já existentes como também nos emergentes, como Copacabana.

Os bondes elétricos também surgiram primeiro na zona sul e seu aparecimento se deu a fim de substituir os bondes puxados por animais. Os próprios carris demarcavam a diferença de classes, já que os de primeira classe se destinavam às camadas ricas e os de segunda classe ao restante da população, estabelecendo diferença entre os usuários (BENCHIMOL, 1990).

Benchimol (1990) explica como no início do século XIX a região da zona sul, de forma geral, foi adquirindo um aspecto majoritariamente residencial. Nessa época, Botafogo era uma das regiões mais procuradas pelas famílias mais ricas do segundo reinado. Aí e nas regiões ao redor estavam grandes mansões que passaram a ser atendidas pelo crescido comércio local. $E$, além disso, companhias especulavam com o solo urbano, gerando certo status, o que fez da zona sul uma região de bairros residenciais que atendiam não mais à nobreza, mas agora às famílias "chiques" da república (BENCHIMOL, 1990, p. 94).

\subsection{0 morador da zona sul carioca}

Assim como no passado, a realidade vivida nessa região no presente possui características próprias, já que, por exemplo, segundo o senso divulgado pelo site da Prefeitura do RJ, os bairros da zona sul possuem os maiores IDHs entre os bairros do Rio de Janeiro, reafirmando o que se pensa sobre eles. Como ressalta Fernandes (2011), ser morador da zona sul acarreta um alto status social.

Algumas características dos moradores da zona sul são tipicamente marcantes e podem ser vistas a olho nu. Um exemplo é a preocupação com o físico, que podemos deduzir ser por conta da noção geográfica, uma vez que a zona sul é rodeada por praias e lugares abertos. Assim, 
como afirma Goldenberg (2002), faz sentido que aí esteja marcada uma preocupação maior com o físico, com o corpo, seja ele modificado, seja ele sarado, definido ou saudável. Gontijo (2002) também traz a noção de morenidade, em que a cor de um bronzeamento natural indica certo grau de saúde, e isso atualmente é valorizado.

O mesmo autor também ressalta a divisão do território da praia, tendo como referência os postos de salvamento. Aí se separam os moradores da zona sul e os não moradores, que incluem até mesmo aqueles que ali residem, porém nas favelas que rodeiam a região. Esse aspecto faz bastante sentido, já que a população que advém de outras regiões, como o subúrbio, aloca-se em postos que ficam próximos aos pontos de ônibus e às estações de metrô (GONTIJO, 2002).

No que se refere à música, na zona sul temos a música popular brasileira (MPB) de Tom Jobim e Vinicius de Moraes, com a canção "Garota de Ipanema" marcada pela letra de uma garota do corpo dourado, que caminha num doce balanço a caminho do mar.

\subsection{Dados da zona sul carioca}

No ano de 2010, segundo o portal da prefeitura, o que os dados verificados pelo IBGE nos mostram é que, da população da zona sul, 239.729 pessoas estavam alocadas na região administrativa de Botafogo e 167.774 na da Lagoa.

A população da região de Botafogo, por sua vez, no período entre 1991 e 2000, teve um decréscimo de 251.668 habitantes para 238.895, e depois, até 2010, um crescimento. Já na região da Lagoa houve apenas decréscimos desde 1991, de 177.072 para 174.062 em 2000 - e depois seguiu decaindo.

No que tange ao rendimento mensal domiciliar dos moradores das regiões administrativas em questão, no ano de 2010, pode-se afirmar, segundo dados adquiridos por meio de pesquisa do IBGE, que a região da zona sul possuía, de forma geral, os maiores valores. Na região administrativa de Botafogo, esse valor chegou a 8.804,51 reais, com a média dos bairros que compõem essa região. Já na média dos bairros da região da Lagoa esse valor foi o maior de todas regiões do município, atingindo $13.750,32$ reais, sendo o bairro que dá o nome à região administrativa aquele com o maior valor de todo o município.

Em 2010, a população da região de Botafogo era composta por 79,6\% de brancos, 4,5\% de negros e $15 \%$ de pardos. Na Lagoa, essa proporção era de $83 \%$ de brancos, $4,2 \%$ de negros e $12,3 \%$ de pardos. A população da região de Botafogo estuda, em média, durante 10 anos, e a população da região da Lagoa estuda, em média, 10,1 anos.

Em 2000, segundo o IBGE, na ordem no índice de desenvolvimento humano municipal, a região da Lagoa se encontrava em segundo lugar e Botafogo em terceiro, perdendo apenas para Copacabana.

Em 2010, segundo dados do IBGE, o número médio de filhos para a região de Botafogo era de 0,59 e o tamanho médio da família era de 2,32 integrantes. Já na região da Lagoa o número de filhos era maior, com 0,68 e o tamanho da família de 2,46 integrantes.

Já na Área de Planejamento 2, em que estão os bairros da zona sul, os deslocamentos para outras regiões são mais frequentes, especialmente para a Área de Planejamento 4, em que estão os bairros da Barra da Tijuca e Jacarepaguá. O deslocamento contrário entre essas duas áreas de planejamento também se observa. No primeiro caso, a porcentagem é de $14,6 \%$, e no segundo, de 10,5\%. 


\section{TEORIA DAS REPRESENTAÇÕES SOCIAIS}

O enfoque teórico deste artigo se encontra no campo de estudos das representações sociais, que surgiu do aprofundamento e refinamento do conceito de representações coletivas de Durkheim (SÁ, 2007). Moscovici (1961) apresentou as representações sociais de maneira formal a partir do desenvolvimento e publicação de sua tese de doutorado, em que investigava como a psicanálise era apropriada na sociedade francesa, sobretudo por grupos de católicos e comunistas.

Moscovici (1978) tinha interesse em saber como o senso comum se formava e guiava as ações das pessoas na sociedade. Para ele, o pensamento social não poderia ser resumido à soma dos pensamentos individuais, ou seja, existe uma construção feita por grupos sociais que representam objetos, de forma que ele ocorre, ao mesmo tempo, em nível individual e coletivo.

Mas o que são as representações sociais? São o produto e também o processo no qual um grupo social reconstitui o real, atribuindo uma ressignificação específica (ABRIC, 1994). Podem ser definidas como conhecimento que o grupo elabora acerca da realidade a fim de melhor conhecê-la e saber lidar com ela, guiando suas ações e práticas.

Assim, as representações sociais permitem que as pessoas conheçam e interpretem o mundo a partir do processo de transformação do não familiar em familiar, uma vez que o novo é assimilado e incorporado aos conhecimentos prévios do grupo (SÁ, 1996). Isso ocorre a partir dos processos de objetivação e ancoragem, que são, respectivamente, o processo de tornar real um esquema conceitual de forma que haja concretude e o processo de integrar o novo a um sistema de crenças já existente (MOSCOVICl, 1978).

Moscovici ressalta a importância do estudo do conhecimento do senso comum, sobretudo no ambiente acadêmico, já que este é uma "modalidade de conhecimento particular que tem por função a elaboração de comportamentos e a comunicação entre indivíduos" (MOSCOVICI, 1978, p. 26). Portanto estudar as representações sociais é investigar a raiz das ideias que permeiam as relações sociais, já que elas direcionam a forma de lidar e se comportar.

Abric (2003) ressalta que as representações não só dão significado, como também orientam, guiam práticas e justificam comportamentos e tomadas de posição. O autor propõe as representações a partir de um duplo sistema estruturado em um núcleo central e um sistema periférico, o que permite melhor estudo e investigação das ideias que os grupos possuem sobre os objetos sociais. Trata-se de uma estrutura interna e dinâmica que organiza as representações.

O duplo sistema proposto por Abric (2003) é composto por um núcleo central que define, cria e estabiliza o conteúdo da representação; enquanto o sistema periférico permite a adaptação dos elementos contextuais à representação, bem como protege o núcleo, resistindo às mudanças de interpretação.

A proposta neste artigo é justamente levantar os cognemas evocados por moradores da zona sul da cidade do Rio de Janeiro, a fim de investigar a representação que eles têm deles mesmos, dos moradores do subúrbio e dos cariocas em geral. Por se tratar de um tema identitário, a teoria da identidade social também integra o enfoque teórico da pesquisa.

\section{TEORIA DA IDENTIDADE SOCIAL}

O sentimento de pertença que as pessoas têm em relação a grupos sociais específicos pode ser definido como identidade social. Tajfel (1982) afirma que as formas de pensar e agir 
das pessoas estão vinculadas às condições sociais a que seus grupos de pertença estão sujeitos. Para o autor, o integrante de determinado grupo social compartilha com os demais integrantes ideias e sentimentos que influenciam de forma direta suas vontades e comportamentos.

O conceito de identidade social está fortemente relacionado ao processo de categorização social, em que o meio social é organizado a partir de informações agrupadas pelo sujeito (TAJFEL, 1972). Essa categorização se dá com base em semelhanças e diferenças das informações do meio, o que permite a sistematização e organização delas (DESCHAMPS; MOLINER, 2009).

Assim, de forma prática, categorias são criadas e utilizadas para apreender a realidade ao redor. O processo de categorização é cognitivo e pode ocorrer com objetos, mas também com pessoas. A maneira como os grupos sociais processam as categorias varia de acordo com o contexto, o que influencia não apenas a forma de pensar, mas também de agir e interagir (TAJFEL, 1972).

A categorização permite que o sujeito diferencie-se dos demais, de forma pessoal e grupal, ou seja, surge uma diferenciação do seu próprio grupo (intragrupo) e dos demais grupos (intergrupos). Esse mecanismo de leitura da realidade ocorre em nível religioso, econômico, étnico, territorial etc. Deste modo, o que ocorre é uma tendência à homogeneidade do grupo e, em contrapartida, uma tendência à heterogeneidade dos demais.

O processo decorrente da categorização é o de comparação social (FESTINGER, 1954), no qual os grupos não só atribuem diferenças entre as categorias, mas também mensuram valor. Esse fato faz com que as pessoas busquem para si uma identidade social que seja positiva.

Consequentemente, a contribuição da teoria da identidade social atrelada ao campo de estudos das representações sociais está na investigação do pensamento social do grupo de moradores da zona sul da cidade do Rio de Janeiro, com a finalidade de saber se há diferenças entre seu intragrupo e o intergrupo dos moradores do subúrbio, bem como do grupo mais amplo que ambas as classes integram, o grupo dos cariocas.

\section{MÉTODO}

\subsection{Participantes}

Participaram da pesquisa 100 sujeitos residentes das regiões da zona sul do Rio de Janeiro, mais especificamente das regiões administrativas de Botafogo e da Lagoa. A população foi dividida em grupos de 50 participantes para cada uma das regiões administrativas, utilizando-se determinados critérios para participação, sendo eles: estar morando há mais de 10 anos na região administrativa ou ter sido criado ali. Essas informações foram obtidas antes do preenchimento dos questionários.

Responderam ao questionário sujeitos de ambos os sexos, dividindo-se da seguinte maneira: dos 100 participantes moradores da zona sul que responderam ao questionário, 57 eram do sexo masculino e tinham uma média de idade de 26,3 anos, e 43 eram do sexo feminino com uma média de idade de 22,4 anos. A média da idade para a população total dessa região foi de 22,6 anos.

Quanto ao estado civil, 11\% dos participantes disseram ser casados, 2\% divorciados e $87 \%$ solteiros. Outro fator identificado foi de que $97 \%$ dos participantes que responderam aos questionários são brasileiros e, desses, $83 \%$ são cariocas. 
Quanto à escolaridade dos participantes que responderam ao questionário, pode-se verificar que a porcentagem de participantes que estavam cursando ou terminaram de cursar o nível superior de ensino foi de $82 \%$. Aqueles que possuíam apenas o nível médio concluído chegaram a 14\%, $2 \%$ não responderam e os outros $2 \%$ possuíam pós-graduação.

Alguns dados sociodemográficos foram obtidos por meio do questionário e a análise deles nos mostra que, quanto à cor da pele dos participantes que responderam ao questionário, $74,23 \%$ se consideravam brancos, $13,4 \%$ se consideravam pardos, $5,15 \%$ se consideravam negros e $3,09 \%$ se consideravam amarelos. Os outros $4,12 \%$ optaram por não declararem a cor de suas peles.

Já quanto à religião dos sujeitos da pesquisa, destaca-se o catolicismo como religião mais praticada, correspondendo a $32 \%$ das respostas. O número de pessoas que afirmaram não ter uma religião foi de 17\%, já o número de espíritas foi de $10 \%$.

No que se refere à renda, as respostas nos indicam que a maioria dos participantes dizem receber rendas acima de $\mathrm{R} \$ 3.000,00$. Os salários até $\mathrm{R} \$ 724,00$ são de $2 \%$ e, entre $R \$ 724,00$ e $\mathrm{R} \$ 1.500,00,1 \%$.

\subsection{Procedimentos}

A aplicação dos questionários foi realizada durante o dia em locais diversos, mais especificamente em pontos de grandes aglomerações da população residente nessas regiões, como shoppings, praias, praças, galerias, centros comerciais, além de uma rede de contatos de pessoas que residem nessas regiões.

Além disso, quanto aos procedimentos éticos no que diz respeito aos seres humanos, foi informado aos participantes da pesquisa que se trata de um estudo sem fins lucrativos, sem remuneração pela participação e cujos resultados individuais são anônimos e confidenciais. Também foi esclarecido que o preenchimento do questionário não é do campo da obrigatoriedade e que a desistência do sujeito de participar da pesquisa poderia ocorrer a qualquer momento, sem custo/dano algum.

\subsection{Instrumentos}

Para a obtenção dos dados necessários à pesquisa, o questionário englobou algumas técnicas que abordaram uma série de questões pertinentes ao tema, entre elas o método de evocações livres tipicamente usado na abordagem estrutural das representações sociais, sendo os termos indutores "cariocas", "moradores da zona sul" e "moradores do subúrbio". O questionário também é composto por escalas de Likert de sete pontos que permitem expressar grau de concordância de um extremo favorável a um desfavorável (MALHORTA, 2006) e questões fechadas sobre os dados sociodemográficos.

\subsection{Análise de dados}

A análise prototípica serviu para levantar os resultados da evocação livre, considerando como critérios de importância a frequência e a ordem de aparição das evocações produzidas pelos participantes (OLIVEIRA et al., 2005), enquanto as escalas de Likert foram analisadas a partir da ANOVA e as questões fechadas foram levantadas a partir de estatística inferencial. 


\section{RESULTADOS}

\subsection{Análise prototípica do termo indutor "cariocas" para moradores da zona sul}

O número total de evocações para o termo indutor "cariocas" entre os sujeitos residentes da zona sul foi de 475. Com essas expressões, foi possível realizar uma categorização quanto aos termos com significado semelhante, chegando-se a 119 termos diferentes. Foram 59 termos evocados apenas uma vez.

Quadro 1 - Análise prototípica do termo indutor "cariocas" para moradores da zona sul

\begin{tabular}{|c|c|c|c|c|c|c|c|}
\hline & & \multicolumn{6}{|c|}{$\begin{array}{l}\text { Ordem média de evocação (OME) } \\
\qquad 3\end{array}$} \\
\hline & & & & & & & \\
\hline \multirow{2}{*}{ 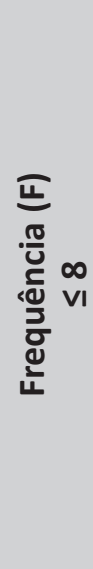 } & + & $\begin{array}{c}\text { Praia } \\
\text { Sol } \\
\text { Simpatia } \\
\text { Samba } \\
\text { Futebol } \\
\text { Alegria } \\
\text { Beleza }\end{array}$ & $\begin{array}{c}\text { OME } \\
1,77 \\
2,61 \\
2,72 \\
2,75 \\
3 \\
2,16 \\
2,5\end{array}$ & $\begin{array}{c}F \\
72 \\
21 \\
22 \\
15 \\
15 \\
12 \\
8\end{array}$ & $\begin{array}{l}\text { Malandro } \\
\text { Gírias } \\
\text { Receptivo } \\
\text { Cerveja } \\
\text { Carnaval }\end{array}$ & $\begin{array}{l}\text { OME } \\
3,04 \\
3,06 \\
3,12 \\
3,57 \\
3,62\end{array}$ & $\begin{array}{c}F \\
25 \\
30 \\
8 \\
14 \\
21\end{array}$ \\
\hline & - & $\begin{array}{c}\text { Chá-mate } \\
\text { Maracanã } \\
\text { Descolado } \\
\text { Calor } \\
\text { Amizade }\end{array}$ & $\begin{array}{c}2,28 \\
2,57 \\
2,8 \\
2,83 \\
2,86\end{array}$ & $\begin{array}{l}7 \\
7 \\
5 \\
6 \\
7\end{array}$ & $\begin{array}{c}\text { Bom humor } \\
\text { Descontraído } \\
\text { Festeiro } \\
\text { Divertido } \\
\text { Copacabana }\end{array}$ & $\begin{array}{c}3,14 \\
3,2 \\
3,57 \\
4,16 \\
4,33\end{array}$ & $\begin{array}{l}7 \\
5 \\
7 \\
6 \\
6\end{array}$ \\
\hline
\end{tabular}

Fonte: Os autores.

No Quadro 1, vemos que o termo indutor "cariocas" para os sujeitos residentes da zona sul obteve como elementos aparentemente centrais "praia", "alegria", "beleza", "sol", "simpatia", "samba" e "futebol". Entre eles, "praia", "simpatia" e "sol" se destacaram como mais centrais, com as maiores frequências e menores ordens médias de evocações.

Na primeira periferia, foram evocados os elementos "malandro", "gírias", "receptivo", "cerveja" e "carnaval". Na segunda periferia, temos os termos "bom humor", "descontraído", "festeiro", "divertido" e "Copacabana". E, na zona de contraste por terem uma ordem média de evocação (OME) baixa, mas com frequência (F) maior ou igual a três, estão os termos "chá-mate", "Maracanã", "descolado", "calor" e "amizade".

\subsection{Análise prototípica do termo indutor "moradores da zona sul" para moradores da zona sul}

Para o termo indutor "moradores da zona sul", o total de termos evocados foi de 444, sendo categorizados em 174 tipos diferentes. E o número de hápax, ou seja, termos evocados uma única vez, foram 95 no total. 
Quadro 2 - Análise prototípica do termo indutor "moradores da zona sul" para moradores da zona sul

\begin{tabular}{|c|c|c|c|c|c|c|c|}
\hline & \multicolumn{6}{|c|}{$\begin{array}{l}\text { Ordem média de evocação (OME) } \\
\leq 2,8\end{array}$} \\
\hline & & \multicolumn{3}{|c|}{ - } & \multicolumn{3}{|c|}{+} \\
\hline \multirow{2}{*}{ 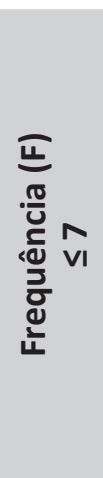 } & + & $\begin{array}{l}\text { Praia } \\
\text { Ricos } \\
\text { Playboy }\end{array}$ & $\begin{array}{c}\text { OME } \\
2,3 \\
2,03 \\
2\end{array}$ & $\begin{array}{l}F \\
47 \\
28 \\
11\end{array}$ & $\begin{array}{l}\text { Ipanema } \\
\text { Dinheiro } \\
\text { Privilegiados } \\
\text { Beleza } \\
\text { Shopping }\end{array}$ & $\begin{array}{l}\text { OME } \\
2,87 \\
2,94 \\
3,11 \\
3,25 \\
3,33\end{array}$ & $\begin{array}{c}\mathrm{F} \\
8 \\
16 \\
9 \\
8 \\
9\end{array}$ \\
\hline & - & $\begin{array}{c}\text { Alegria } \\
\text { Classe média } \\
\text { Patricinhas } \\
\text { Educados } \\
\text { Cultos }\end{array}$ & $\begin{array}{c}1,8 \\
2,4 \\
2,43 \\
2,66 \\
2,8\end{array}$ & $\begin{array}{l}5 \\
5 \\
7 \\
6 \\
5\end{array}$ & $\begin{array}{l}\text { Esnobes } \\
\text { Gírias } \\
\text { Bom humor } \\
\text { Metidos }\end{array}$ & $\begin{array}{c}2,83 \\
2,86 \\
3 \\
3\end{array}$ & $\begin{array}{l}6 \\
7 \\
6 \\
6\end{array}$ \\
\hline
\end{tabular}

Fonte: Os autores.

No Quadro 2, os termos que se encontram no quadrante do núcleo central e que seriam centrais são "playboy", "ricos" e "praia", sendo "praia" o termo com a maior frequência entre todos. Já na primeira periferia vemos os elementos "Ipanema", "dinheiro", "privilegiados", "beleza" e "shopping", ainda com altas frequências, mas agora não tão prontamente lembrados.

Na segunda periferia, encontramos "esnobes", "gírias", "bom humor" e "metidos", com baixas frequências e baixas OME. Na zona de contraste estão as palavras "alegria", "classe média", "patricinhas", "educados" e "cultos".

\subsection{Análise prototípica do termo indutor "moradores do subúrbio" para os moradores da zona sul}

O total de termos evocados para o termo indutor "moradores do subúrbio" foi de 424, a partir dos quais foram criadas 157 categorias de termos diferentes. Foi de 91 o número de termos evocados uma única vez.

Quadro 3 - Análise prototípica do termo indutor "moradores do subúrbio" para os moradores da zona sul

\begin{tabular}{|c|c|c|c|c|c|c|c|}
\hline & \multicolumn{6}{|c|}{$\begin{array}{l}\text { Ordem média de evocação (OME) } \\
\qquad \leq 3\end{array}$} \\
\hline & & \multicolumn{3}{|c|}{ - } & \multicolumn{3}{|c|}{+} \\
\hline \multirow[t]{2}{*}{ 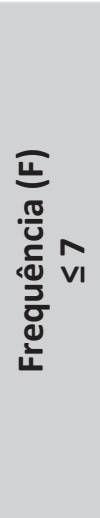 } & + & $\begin{array}{c}\text { Samba } \\
\text { Humildade } \\
\text { Gírias } \\
\text { Pobre } \\
\text { Churrasco } \\
\text { Transporte público } \\
\text { Pagode }\end{array}$ & $\begin{array}{c}\text { OME } \\
3 \\
2,43 \\
2,58 \\
2,4 \\
2,5 \\
1,62 \\
2,37\end{array}$ & $\begin{array}{c}F \\
15 \\
14 \\
12 \\
10 \\
10 \\
8 \\
8\end{array}$ & $\begin{array}{c}\text { Trabalhadores } \\
\text { Funk } \\
\text { Alegria } \\
\text { Festeiro } \\
\text { Calor } \\
\text { Trem }\end{array}$ & $\begin{array}{c}\text { OME } \\
3,08 \\
3,1 \\
3,12 \\
3,12 \\
3,36 \\
3,37\end{array}$ & $\begin{array}{c}F \\
26 \\
10 \\
8 \\
8 \\
14 \\
8\end{array}$ \\
\hline & - & $\begin{array}{c}\text { Dificuldades } \\
\text { Casas } \\
\text { Metro } \\
\text { Ônibus }\end{array}$ & $\begin{array}{c}2,17 \\
2,6 \\
2,6 \\
2,83\end{array}$ & $\begin{array}{l}6 \\
5 \\
5 \\
6\end{array}$ & $\begin{array}{c}\text { Violência } \\
\text { Barulhentos } \\
\text { Feliz } \\
\text { Esforçados }\end{array}$ & $\begin{array}{c}3,14 \\
3,16 \\
3,4 \\
3,8\end{array}$ & $\begin{array}{l}7 \\
6 \\
5 \\
5\end{array}$ \\
\hline
\end{tabular}

Fonte: Os autores. 
No primeiro quadrante do Quadro 3 da análise, verificamos os termos supostamente centrais como sendo "samba", "transporte público", "pagode", "pobre", "humildade", "churrasco" e "gírias". Entre eles, os termos com maiores frequências são "samba" e "humildade", indicando sua maior centralidade em relação aos demais. Na primeira periferia, vemos os elementos "trabalhadores", "funk", "alegria", "festeiro", "calor" e "trem" ainda com altas frequências, mas já com altas OME.

Na segunda periferia, encontramos os elementos "violência", "barulhentos", "feliz" e "esforçados" com menores frequências de evocação e alta OME. E, por fim, na zona de contraste, verificamos a importância dos termos "dificuldades", "casas", "metrô" e "ônibus" para algum possível subgrupo, já que possuem baixa OME.

Tabela1 - Escores relativos às características dos cariocas segundo moradores da zona sul em escalas de Likert de sete pontos, variando de um a sete, em que um significa "não possui essa característica" e sete significa "é extremamente". N=100. Rio de Janeiro.

\begin{tabular}{cc}
\hline Características & Média das respostas de moradores da zona sul \\
\hline Trabalhadores & 5,11 \\
\hline Bem-humorados & 5,01 \\
\hline Receptivos & 4,77 \\
\hline Preguiçosos & 4,05 \\
\hline Acomodados & 4,21 \\
\hline Responsáveis & 4,92 \\
\hline Malandros & 4,54 \\
\hline Engraçados & 4,69 \\
\hline Descontraídos & 5,52 \\
\hline Informais & 4,47 \\
\hline Mantêm os valores & 4,99 \\
\hline da família & 6,15 \\
\hline Preocupados com a & 3,51 \\
\hline saúde do seu corpo & 5,00 \\
\hline Vulgares & 2,96 \\
\hline Apressados & \\
\hline Ladrões & \\
\hline
\end{tabular}

Fonte: Os autores.

A Tabela 1 apresenta resultados do pensamento de moradores da zona sul acerca dos cariocas a partir de escalas de Likert de sete pontos, em que um significa "não possui essa característica" e sete significa "é extremamente". Esses resultados foram analisados a partir da ANOVA.

Assim, algumas características definidas previamente foram apresentadas aos participantes da pesquisa para que eles demonstrassem seus graus de concordância entre dois extremos de uma escala.

Quanto aos resultados, no termo "trabalhadores", podemos ver que os moradores da zona sul consideram os cariocas "trabalhadores" $(5,11)$, bem como "bem-humorados" $(5,01)$, termo que aparece de forma tímida e similar no padrão de respostas, não atingindo valores altos e, por 
isso não, se identificando como forte característica dos cariocas de acordo com os moradores da zona sul.

A característica dos cariocas como "receptivos" aparece de forma fraca $(4,77)$, próxima do meio da escala. "Preguiçosos" $(4,05)$ e "acomodados" $(4,21)$, também pelas baixas médias, indicam que não são características marcantes dos cariocas para os participantes da pesquisa. As características "responsáveis" $(4,92)$, "malandros" $(4,54)$ e "engraçados" $(4,69)$ também acompanham o grupo de adjetivos com respostas próximas ao meio da escala.

"Descontraído" $(5,52)$ aparece como algo associado ao pensamento social dos participantes acerca dos cariocas, mas "informais" $(4,47)$ e "mantêm os valores da família" $(4,99)$ seguem o padrão médio de respostas.

Todavia não se pode afirmar o mesmo quanto a "preocupados com a saúde do corpo" $(6,15)$. Aqui vemos uma indicação desse traço como algo fortemente associado aos cariocas pelos moradores da zona sul, resultado esse também destacado na literatura (GOLDENBERG, 2002; GONTIJO, 2002).

"Apressados" $(5,00)$ também soa de forma importante no pensamento acerca dos cariosas, mas com média inferior a "preocupados com a saúde do corpo" $(6,15)$. Já a característica "vulgares" $(3,51)$, de forma oposta, não parece ser algo essencial ao pensar no carioca, assim como "ladrões" $(2,96)$.

Tabela 2 - Escores relativos à pertença dos participantes da pesquisa em escalas de Likert de sete pontos, variando de um a sete, em que um significa "não me sinto nada" e sete significa "me sinto totalmente". $\mathrm{N}=100$. Rio de Janeiro.

\begin{tabular}{cc}
\hline O quanto se sente? & Zona sul \\
\hline Brasileiro & 5,89 \\
\hline Do Estado do RJ & 5,53 \\
\hline Carioca & 5,93 \\
\hline Do seu bairro & 5,59 \\
\hline
\end{tabular}

Fonte: Os autores.

Na Tabela 2, os itens de Likert abarcam a sensação de pertencer ao local de moradia, tanto em um nível local como em um nível mais abrangente. Podemos perceber que, de acordo com as médias, existe, quanto à sensação de pertença ao Brasil, uma valoração positiva, porém não muito destacada, visto que gira em torno de 5,89.

Já quanto à relação de pertença ao Estado do RJ, vemos que as médias $(5,53)$ mostram também uma relação positiva de pertença, porém mais uma vez fora de um valor de destaque, mostrando não ser tão forte essa sensação de pertença.

Outra relação analisada se deu com referência ao município do Rio de Janeiro, em termos de sentir-se carioca. Percebemos, mais uma vez, a relação de pertença positiva e em um nível relativamente mais alto em comparação a todas as pertenças analisadas, apesar de não serem valores de destaque, beirando valores intermediários $(5,93)$.

Em nível de bairro, os moradores da zona sul indicam uma valoração positiva com relação aos seus bairros de moradia, apresentando 5,59 de média, demonstrando que se sentem pertencer aos seus bairros. 


\section{DISCUSSÃO}

Os resultados desta pesquisa salientam a forte conexão entre o campo de estudo das representações sociais e a teoria da identidade social, uma vez que os participantes moradores da zona sul associam a si mesmos mais termos positivos ("ricos", "privilegiados", "educados" e "cultos") e alguns mais negativos ao grupo de moradores do subúrbio ("pobre", "dificuldades", "violência" e "barulhentos").

Esses resultados podem ser articulados com a teoria da identidade social, em que Tajfel (1982) afirma que existe uma tendência na qual as pessoas buscam para si uma identidade social que seja positiva e que não apenas diferencie o intragrupo do intergrupo como também atribua valor para ambos.

Os resultados referentes aos itens de Likert sobre os cariocas possuem escores de médias de respostas maiores nos itens que condizem com as evocações relativas tanto aos moradores da zona sul ("bem-humorados") quanto do subúrbio ("trabalhadores").

O mesmo pode ser visto no que se refere à representação dos cariocas, em que há certo equilíbrio nas evocações que surgiram, o que é compreensível, uma vez que ser carioca abarca tanto moradores da zona sul quanto moradores do subúrbio, sendo uma categoria mais ampla que abarca ideias de ambos os grupos. Esse equilíbrio é notável ao observar que existem quatro evocações em comum entre cariocas e moradores da zona sul ("praia", "beleza", "bom humor" e "gírias") e quatro evocações em comum entre cariocas e moradores do subúrbio ("samba", "alegria", "calor" e "gírias"). Consequentemente, na representação que os moradores da zona sul fazem deles mesmos, dos moradores do subúrbio e dos cariocas, a única evocação em comum para os três grupos foi "gírias".

Isso pode indicar que, embora os participantes da pesquisa representem os cariocas como uma categoria maior que engloba moradores da zona sul e do subúrbio, existem diferenças acentuadas entre essas duas subcategorias que foram destacadas nos resultados, uma vez que há mais evocações em comum com os cariocas (quatro evocações) do que com moradores do subúrbio, em que há apenas uma evocação em comum.

Contudo é interessante notar que os participantes da pesquisa se sentem muito mais cariocas e brasileiros do que do seu próprio bairro ou do Estado do Rio de Janeiro. Esses dados podem estar associados ao fato de, na teoria da identidade social, os sujeitos buscarem uma pertença positiva, o que é revelado na forte associação da cidade do Rio de Janeiro como a mais famosa do estado, bem como sua exposição internacional. Ou seja, apesar de os moradores da zona sul possuírem quatro fontes de pertença positiva (em nível nacional, estadual, de cidade e bairro), as mais relevantes e que acarretam mais status (FERNANDES, 2011), sendo reconhecidas mundialmente, são as esferas do brasileiro e do carioca, sobressaindo sobre o pertencer ao bairro da zona sul ou mesmo ao Estado do Rio de Janeiro.

Assim, na análise da estrutura representacional do intragrupo moradores da zona sul e do intergrupo moradores do subúrbio, chegamos também a uma estrutura identitária dos participantes, na medida em que as representações sociais dão às identidades sociais uma forma de entender como se categorizam os grupos na sociedade, e as identidades dão às representações sociais uma forma de entender como os sujeitos organizam os espaços no seio dos quais elas serão criadas e atualizadas sobre toda sorte de objetos da sociedade. 
Em síntese, a representação e a identidade dos moradores da zona sul aparecem atreladas a características positivas e distintas da representação dos moradores do subúrbio. Além disso, aparecem também como um recorte de uma categoria maior, a do carioca.

Resumindo, o objetivo deste artigo foi delinear a estrutura representacional que o morador da zona sul faz em nível intra e intergrupal, demonstrando que, de acordo com a localidade, pode haver diferentes níveis de pensamentos e pertencimentos.

\section{REFERÊNCIAS}

ABRIC, Jean-Claude. Abordagem estrutural das representações sociais: desenvolvimentos recentes. In: CAMPOS, Pedro H. F.; LOUREIRO, Marcos C. da S. (Org.). Representações sociais e práticas educativas. Goiânia: Editora da UCG, 2003. p. 37-57.

ABRIC, Jean-Claude. Pratiques sociales et représentations. Paris: Presses Universitaires de France, 1994.

BENCHIMOL, Jaime Larry. Pereira Passos: um Haussmann tropical: a renovação urbana da cidade do Rio de Janeiro no início do século XX. Rio de Janeiro: Prefeitura, Secretaria Municipal de Cultura, Turismo e Esportes, Departamento Geral de Documentação e Informação Cultural, 1990.

CARDOSO, Elizabeth Dezouzart. Estrutura urbana e representações: a invenção da Zona Sul e a construção de um novo processo de segregação espacial no Rio de Janeiro nas primeiras décadas do século XX. GeoTextos, Salvador, BA, v. 6, n. 1, p. 73-88, jul. 2010. Disponível em: https://rigs.ufba.br/index.php/ geotextos/article/view/4306/3165.

DESCHAMPS, Jean-Claude; MOLINER, Pascal. A identidade em Psicologia Social: dos processos identitários às representações sociais. Petrópolis, RJ: Vozes, 2009.

FEIJÃO, Rosane. As praias e as transformações de sensibilidade no Rio de Janeiro nos anos 1920. In: CONGRESSO DE ESTUDANTES DE PÓS-GRADUAÇÃO EM COMUNICAÇÃO - CONECO, 6., 2013, Rio de Janeiro. Anais [...]. Rio de Janeiro, 2013.

FERNANDES, Nelson. O rapto ideológico da categoria subúrbio: Rio de Janeiro 1858|1945. Rio de Janeiro: Apicuri, 2011.

FESTINGER, Leon. A theory of social comparison processes. Human Relations, v. 7, n. 2, p. 117-40, 1954. Disponível em: http://journals.sagepub.com/doi/abs/10.1177/001872675400700202?journal Code=huma.

GOLDENBERG, Mirian. Nu \& vestido: dez antropólogos revelam a cultura do corpo carioca. Rio de Janeiro: Record, 2002.

GONTIJO, Fabiano. Carioquice ou carioquidade? Ensaio etnográfico das imagens identitárias cariocas. In: GOLDENBERG, Mirian (Org.). Nu \& vestido: dez antropólogos revelam a cultura do corpo carioca. Rio de Janeiro: Record, 2002. p. 41-77.

MALHORTA, Naresh. Pesquisa de marketing: uma orientação aplicada. Tradução: Laura Bocco. 4. ed. Porto Alegre: Bookman, 2006.

MOSCOVICl, Serge. A representação social da Psicanálise. Rio de Janeiro: Zahar, 1978.

MOSCOVICI, Serge. La psychanalyse, son image et son public. Paris: PUF, 1961. 
OLIVEIRA, Denise Cristina; MARQUES, Sergio C.; GOMES, Antônio Marcos T.; TEIXEIRA, Maria Cristina T. V. Análise de evocações livres: uma técnica de análise estrutural das representações sociais. In: MOREIRA Antônia S. P.; CAMARGO, Brígido V.; JESUÍNO, Jorge C.; NÓBREGA, Sheva M. (Ed.). Perspectivas teóricometodológicas em representações sociais. João Pessoa, PB: UFPB, 2005. p. 573-603.

SÁ, Celso Pereira. As representações sociais na história recente e na atualidade da psicologia social. In: JACÓ-VILELA, Ana Maria; FERREIRA, Arthur Arruda Leal; PORTUGAL, Francisco Teixeira (Org.). História da psicologia: rumos e percursos. 2. ed. rev. e ampl. Rio de Janeiro: Nau, 2007. p. 587-602.

SÁ, Celso Pereira. Núcleo central das representações sociais. Petrópolis, RJ: Vozes, 1996.

TAJFEL, Henri. Grupos humanos e categorias sociais I. Lisboa: Livros Horizonte, 1982.

TAJFEL, Henri. La catégorisation sociale. In: Serge Moscovici (Org.). Introduction à la Psychologie Sociale. Paris: Larousse Université, 1972. v. 1.

\section{Sobre os autores:}

Thamiris Marques: Doutora em Psicologia Social. Professora do Departamento de Fundamentos em Psicologia do Instituto de Psicologia da Universidade do Estado do Rio de Janeiro (UERJ). E-mail: thamiris_marques@hotmail.com. Orcid: http://orcid.org/0000-0003-3543-1444

Rosana Ferreira Chalegre: Mestre em Psicologia Social pela Universidade do Estado do Rio de Janeiro (UERJ). E-mail: rosanachalegre@hotmail.com, Orcid: http://orcid.org/0000-0002-6256-5299

Álvaro Rafael Peixoto: Mestre em Psicologia Social pela Universidade do Estado do Rio de Janeiro (UERJ). E-mail: alvarorafael.peixoto@gmail.com, Orcid: https://orcid.org/0000-0002-1480-7919

Rafael Pecly Wolter: Doutor em Psicologia pela Université Paris Descartes, Paris V. Professor titular da Universidade Federal do Espírito Santo (UFES).E-mail: rafaelpeclywolter@gmail.com, Orcid: http://orcid.org/0000-0003-1633-2141 